\title{
Emotion Regulation as a Pathway Connecting Early Life Adversity and Inflammation in Adulthood: a Conceptual Framework
}

\author{
Ambika Mathur $^{1}$ (D) Jacinda C. Li ${ }^{2} \cdot$ Sarah R. Lipitz ${ }^{1}$ Jennifer E. Graham-Engeland ${ }^{1}$
}

Accepted: 6 January 2022 / Published online: 23 February 2022

(c) The Author(s), under exclusive licence to Springer Nature Switzerland AG 2022

\begin{abstract}
Chronic inflammation is implicated in a variety of diseases (e.g., cardiovascular disease and cancer). Much evidence suggests that early life adversity (ELA), such as maltreatment or neglect, can increase risk for inflammation in adulthood. ELA may program proinflammatory activity via its effects on brain areas involved in emotion regulation. Of multiple emotion regulation strategies, some are considered maladaptive (e.g., expressive suppression), while others are generally adaptive (e.g., cognitive reappraisal). We propose a conceptual framework for how emotion regulation tendencies may affect vulnerability or resilience to inflammation in adults who experienced adversity in childhood and/or adolescence. In support of this framework, we summarize evidence for the relationships between emotion dysregulation and higher inflammation (i.e., vulnerability), as well as between cognitive reappraisal and lower inflammation (i.e., resilience), in healthy adults with a history of ELA. Plausible neurobiological, physiological, psychosocial, and ELA-specific factors, as well as interventions, contributing to these associations are discussed. Strengths and limitations of the extant research, in addition to ideas for future directions, are presented.
\end{abstract}

Keywords Early life adversity $\cdot$ Emotion regulation $\cdot$ Cognitive reappraisal $\cdot$ Inflammation $\cdot$ Vulnerability $\cdot$ Resilience

\section{Introduction}

Chronic inflammation-as indicated by persistent lowgrade elevations in peripheral inflammatory markers-is a risk factor for multiple diseases associated with aging, including cardiovascular disease (CVD) and arthritis (Irwin \& Rothermundt, 2012; Piazza et al., 2010). Ongoing psychological stress is related to dysregulation of the hypothalamic-adrenal-pituitary (HPA) axis (a primary output of which is the hormone cortisol) and, in turn,

Ambika Mathur

ambikam08@gmail.com

Jacinda C. Li

jacinda.c.li@gmail.com

Sarah R. Lipitz

sr15291@psu.edu

Jennifer E. Graham-Engeland

jeg32@psu.edu

1 Department of Biobehavioral Health, The Pennsylvania State University, University Park, PA, USA

2 Department of Human Development and Family Studies, The Pennsylvania State University, University Park, PA, USA changes in inflammatory processes (for a more detailed review, see Miller et al., 2007). Long-term and severe stressor exposure is related to elevated levels of peripheral inflammatory markers, such as the cytokine interleukin (IL)-6 and acute phase protein C-reactive protein (CRP; Glaser \& Kiecolt-Glaser, 2005; Li \& Danese, 2018). Ultimately, the persistent low-grade inflammation indicated by such markers is considered a potential mechanism underlying chronic disease and health disparities (see Ferruci \& Fabbri, 2018).

Considerable research has found strong associations between early life adversity (ELA), which can be defined as stressful or traumatic experiences endured in childhood or adolescence, and inflammation in adulthood (Deighton et al., 2018; Fagundes \& Way, 2014). ELA may program the immune system such that proinflammatory activity is primed into adulthood; these resulting proinflammatory tendencies may be exacerbated by the tuning of neural circuits implicated in several psychological processes, such as emotion regulation (Agorastos et al., 2019; Miller et al., 2011). Compelling evidence also suggests that ELA can affect the development and functional connectivity among brain areas critical for emotion regulation (e.g., the prefrontal 
cortex [PFC], hippocampus, and amygdala), in addition to the attainment of appropriate emotion regulation skills, resulting in heightened inflammatory reactivity to stress (Chiang et al., 2015; Crowell et al., 2015; Danese \& McEwen, 2012; Taylor et al., 2011). Thus, it is possible that emotion regulation may affect associations between ELA and inflammation in adulthood, especially via stress response processes.

Emotion regulation refers to the ability to shape the expression of emotion(s) (see Gross, 2015; Webb et al., 2012). The process model of emotion regulation distinguishes five temporally separate emotion regulation processes: situation selection, situation modification, attentional deployment (e.g., distraction, concentration), cognitive change (e.g., cognitive reappraisal), and response modulation (e.g., expressive suppression; for review, see Gross \& Thompson, 2007). For example, under certain circumstances, environmental factors can be chosen and/ or altered, such as by removing oneself from a stressful situation, whereas attentional deployment involves directing attention to a given aspect of a situation to change or elicit emotional responses. Cognitive change can occur when an individual modifies their appraisal of a situation, such as to consider a situation to be less threatening or self-relevant (helping to upregulate positive emotions or to downregulate negative emotions and physiological responses); in contrast, response modulation can be used to change an emotional response after it has developed, such as by using negative health behaviors to numb negative emotions or using positive health behaviors to mitigate physiological stress responses (Gross, 2015). Although the utility of each strategy may depend on the situation (see Aldao, 2013; Bonanno et al., 2004), some strategies are generally associated with less beneficial outcomes in the long term. For example, expressive suppression involves inhibiting one's emotion expression and is generally associated with negative mental and physical health outcomes, such as mood disorders and CVD (for review, see Gross, 2015; Hu et al., 2014). Accordingly, emotion dysregulation-which refers to the inappropriate shaping of emotion based on context, goals, or demands - has been linked to heightened physiological reactivity, as well as other mental and physical health issues (see Crowell et al., 2015; DeSteno et al., 2013; Ganguly \& Brenhouse, 2015). Therefore, emotion dysregulation may not only be a consequence of ELA, but also confer greater vulnerability to inflammation throughout the lifespan (Miller et al., 2011).

Not every individual with a history of ELA manifests emotion dysregulation and/or chronic inflammation in adulthood. Many individuals demonstrate resilience, which can be defined as positive adaptation to extreme stress (for review, see Dunkel-Schetter \& Dolbier, 2011; Southwick et al., 2014; Zautra et al., 2008). Broadly, flexible use of any emotion regulation strategy may be most adaptive (Ford et al., 2019), as opposed to reliance on just strategy. Among the different categories of emotion regulation, however, cognitive reappraisal is one of the most studied, with evidence suggesting it may contribute to resilience to the negative health consequences of ELA (Feder et al., 2019; Meng et al., 2018; Polizzi \& Lynn, 2021). As an antecedent-focused strategy, cognitive reappraisal involves changing one's evaluation of a situation before an emotional response is fully activated, ${ }^{1}$ a pattern which has been associated with reduced physiological dysregulation and, in turn, decreased risk for chronic disease (DeSteno et al., 2013; Gross, 2015). Further, cognitive reappraisal has been shown to be one of the most adaptive emotion regulation strategies, as compared to processes that involve adjusting one's attentional focus (e.g., distraction or concentration) or adjusting one's response (e.g., suppression; Webb et al., 2012). Thus, particular evidence suggests that use of cognitive reappraisal may help foster resilience to heightened inflammatory activity in individuals with a history of ELA by mitigating the effects of stress on inflammation (Feder et al., 2019; Troy \& Mauss, 2011).

\section{The Proposed Conceptual Framework}

The conceptual framework for this review draws on the biological embedding of childhood adversity model proposed by Miller et al. (2011), ${ }^{2}$ with a focus on emotion regulation tendencies as drivers of vulnerability (i.e., via emotion dysregulation) or resilience (i.e., via cognitive reappraisal) to inflammation in healthy adults with a history of ELA. Additionally, we propose a testable conceptual model (see Fig. 1) that can inform future empirical research to examine ELA, emotion regulation, and inflammatory activity in the same sample. Only one empirical study to our knowledge examined a moderation model: Results demonstrated that higher levels of self-reported resilience resources, which included a measure of healthy emotional expression, were linked with lower plasma IL-6 levels in individuals with a greater amount of retrospective, self-reported ELA (Gouin

\footnotetext{
${ }^{1}$ Cognitive reappraisal involves reinterpreting or reevaluating the emotional situation and/or one's goals. During a difficult job interview, for example, reappraisal could involve convincing oneself that the interviewer is trained to not give positive feedback, thereby helping to avoid worry (McRae and Gross, 2020).

2 The biological embedding model proposes that ELA becomes programmed into immune cells, resulting in proinflammatory activity that, in turn, is exacerbated by negative health behaviors (e.g., high threat vigilance, impaired self-regulation) and hormonal dysregulation. These behavioral and hormonal alterations may also be a consequence of ELA (Miller et al., 2011).
} 


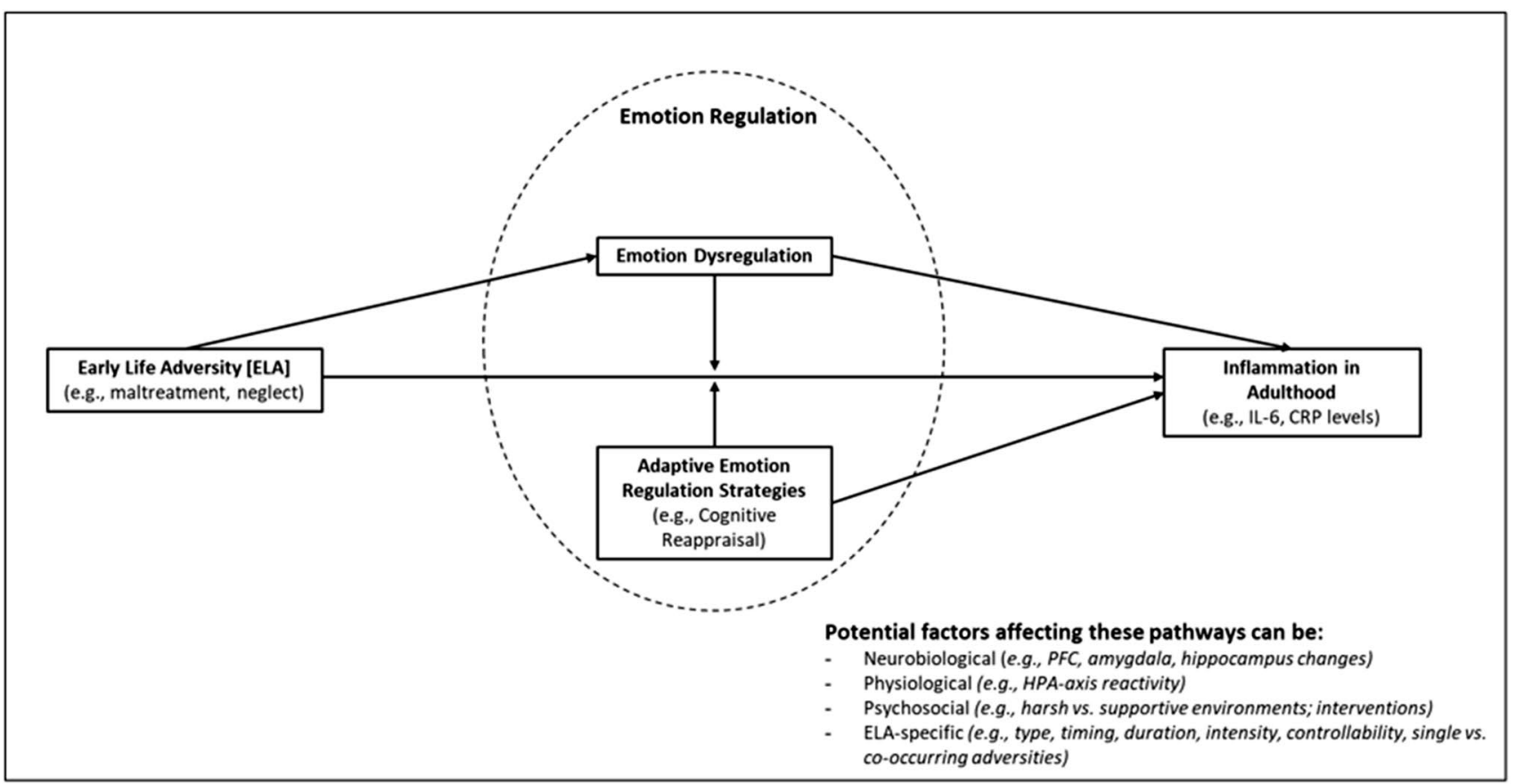

Fig. 1 Model of emotion regulation tendencies as potential drivers of vulnerability or resilience to inflammation in adults with a history of early life adversity (ELA). Our conceptual framework proposes that emotion dysregulation can mediate connections between ELA and higher inflammation (i.e., vulnerability). Emotion dysregulation could also exacerbate associations between ELA and inflammation.

et al., 2017). We aim to integrate the literatures examining risky and protective emotion regulation tendencies that can affect linkages between ELA and health outcomes related to inflammation, such as perceived stress, negative affect, and patterns of cortisol output.

Linkages between ELA (e.g., maltreatment, trauma) and elevated inflammation in adulthood are well established (e.g., see Baumeister et al., 2016; Chiang et al., 2015; Coelho et al., 2014; Danese \& McEwen, 2012; Deighton et al., 2018; Fagundes et al., 2013; Kuhlman et al., 2017; Li \& Danese, 2018; Miller et al., 2011). Therefore, our conceptual framework incorporates review and empirical literatures examining postnatal adversity experienced in childhood and/or adolescence as a predictor of emotion dysregulation in adults, in addition to the literatures examining emotion dysregulation as a predictor of inflammation in adults. The potential for emotion dysregulation to exacerbate connections between ELA and inflammation is also considered. Additionally, we describe how the specific emotion regulation strategy of cognitive reappraisal could buffer associations between ELA and inflammation in adults by discussing studies examining the moderating effects of reappraisal on ELA and other relevant outcomes, as well as direct associations between reappraisal and inflammation. We focus on cognitive reappraisal for conceptual reasons
In contrast, adaptive emotion regulation strategies such as cognitive reappraisal use may buffer connections between ELA and inflammation (i.e., resilience). Cognitive reappraisal use may also predict lower inflammation. Factors that may affect these pathways of vulnerability or resilience can be neurobiological, physiological, psychosocial, and/ or ELA-specific

noted above and because the most relevant research linking resilient emotion regulation and inflammation has focused on this strategy. However, the impact of behaviors that utilize cognitive change strategies (e.g., mindfulness meditation) on inflammation is also discussed. A general review of plausible neurobiological, physiological, psychosocial, and ELAspecific factors contributing to these associations is provided.

Our examination of the literature focused on healthy adults because of the potential confounding of the constructs of interest with comorbid psychopathology and/or physical health disorders (e.g., immune conditions), with the understanding of variability in outcomes among healthy populations. As such, the potential for health conditions (e.g., obesity, psychopathology) and/or behaviors (e.g., substance use) to act as mediators of the pathways of interest are beyond the scope of our proposed framework, but discussed elsewhere (e.g., see Baldwin \& Danese, 2019; Deighton et al., 2018; Duffy et al., 2018; Herzog \& Schmahl, 2018; Miller et al., 2011; VanTieghem \& Tottenham, 2018). Finally, we present strengths and limitations of the literature, in addition to ideas for future directions.

Peer-reviewed empirical and review articles based on the criteria presented above were found using a variety of search engines (e.g., PubMed, PsycINFO). Studies focusing on ELA as a predictor of emotion dys/regulation in adults, 
as well as studies examining emotion dys/regulation as predictor of inflammation in adults, were included. To find additional articles, reference lists of obtained articles were examined, and Google Scholar alerts were set up for the relationships of interest.

\section{Early Life Adversity and Emotion Regulation}

\section{Early Life Adversity and Emotion Dysregulation/ Regulation}

Table 1 presents all of the empirical studies examining associations between ELA and emotion dys/regulation in adults to our knowledge. This table summarizes study type (e.g., cross-sectional, experimental, neuroimaging), sample type (noting age, gender, race, and other demographic details if specified), exclusion criteria if used, and covariates used. Table 1 also summarizes the type of ELA measure utilized in the study (noting what type of ELA experience was most prevalent in the sample if it was clearly specified), and the type of emotion dys/regulation measure used. Lastly, Table 1 summarizes the main results with regard to direction of associations between ELA and emotion regulation.

In general, retrospective, self-reported ELA (e.g., maltreatment or trauma) was found to be associated with selfreported emotion dysregulation in adults across several cross-sectional studies (Bradley, Westen, et al., 2011; Charak et al., 2019; Dunn et al., 2018; Janiri et al., 2021; Poole et al., 2018; Tinajero et al., 2020) and as summarized in one review article (Dvir et al., 2014). Only one study to our knowledge examined emotion dysregulation as a moderator and found that self-reported expressive suppression exacerbated the association between low to moderate reported ELA and perceived chronic stress (Kalia \& Knauft, 2020). In aggregate, the extant literature suggests connections between ELA and emotion dysregulation in adults.

\section{Potential Factors Contributing to Associations Between Early Life Adversity and Emotion Dysregulation in Adulthood}

Several reviews have discussed the neurobiological consequences of ELA. Core findings regarding the development/ maturation and functional connectivity among the amygdala, PFC, and hippocampus in relation to emotion dysregulation are summarized here (for a review of other affected brain regions, see Hein \& Monk, 2017). ELA experienced during sensitive periods of development can affect the maturation of these neural structures, which are critically involved in the appraisal and interpretation of potentially threatening stimuli (see Krugers et al., 2016; Teicher et al., 2016). The
PFC is particularly vulnerable to the negative effects of ELA because of its prolonged development, which is in contrast to the amygdala: The reactivity of the amygdala in childhood leads to an early sensitive period consisting of heightened vulnerability to stress (see Heim \& Binder, 2012; Pechtel \& Pizzagalli, 2011). Further, ELA may increase amygdalar responding to emotional stimuli, which may be adaptive in early threatening environments (see Hein \& Monk, 2017; Teicher \& Samson, 2016). ELA may also affect the size of these neural structures: Adults with a history of ELA have evidenced reduced hippocampal and PFC volumes (see Danese \& McEwen, 2012; Teicher et al., 2016). Amygdala volume may increase in response to adversity experienced in childhood yet decrease in response to greater sensitization to stress in adulthood (see Teicher \& Samson, 2016). It thus seems clear that adversity experienced during critical periods of development can disrupt the appropriate growth and functioning of the PFC, amygdala, and hippocampus.

ELA may also disrupt the functional connectivity among the hippocampus, PFC, and amygdala, subsequently altering emotion responding and stress sensitivity (see Herzberg \& Gunnar, 2020; Krugers et al., 2016; Teicher et al., 2016). Amygdala reactivity to emotional or potentially threatening stimuli has been shown to be consistently heightened in individuals with a history of ELA (see Teicher \& Samson, 2016). Further, impairments in the amygdala-prefrontal (i.e., frontolimbic) circuitry may be linked with emotion dysregulation in individuals with a history of ELA; whereas successful emotion regulation is associated with greater functional coupling between the PFC and amygdala (i.e., increased PFC activity with decreased amygdala activity), ELA may reduce this functional connectivity (see Cohodes et al., 2020; Duffy et al., 2018; Kim et al., 2011; VanTieghem \& Tottenham, 2018). Thus, ELA may wire the brain to manifest an exaggerated response to emotional stimuli.

Psychosocial factors may also help explain how ELA can predispose emotion dysregulation in adulthood. ELA may not only disrupt the attainment of appropriate emotion regulation skills, but also exacerbate the potential neurobiological sequelae of ELA (see Cicchetti \& Rogosch, 2009; Dvir et al., 2014). For example, a persistent threatening environment could maintain amygdala hyperreactivity, as well as the habitual use of expressive suppression. Further, conflictual families that invalidate emotions or make emotion expression seem inappropriate can lead to emotion dysregulation throughout life (Repetti et al., 2002; Warner et al., 2020). Neglectful environments can also affect the development of secure attachments with caregivers, which can further contribute to emotion dysregulation across the lifespan (Sroufe, 2005). Similar to the biological adaptations seen in response to threatening environments, ELA can contribute to selfregulation patterns that may be behaviorally and physiologically adaptive in unstable environments but maladaptive for 


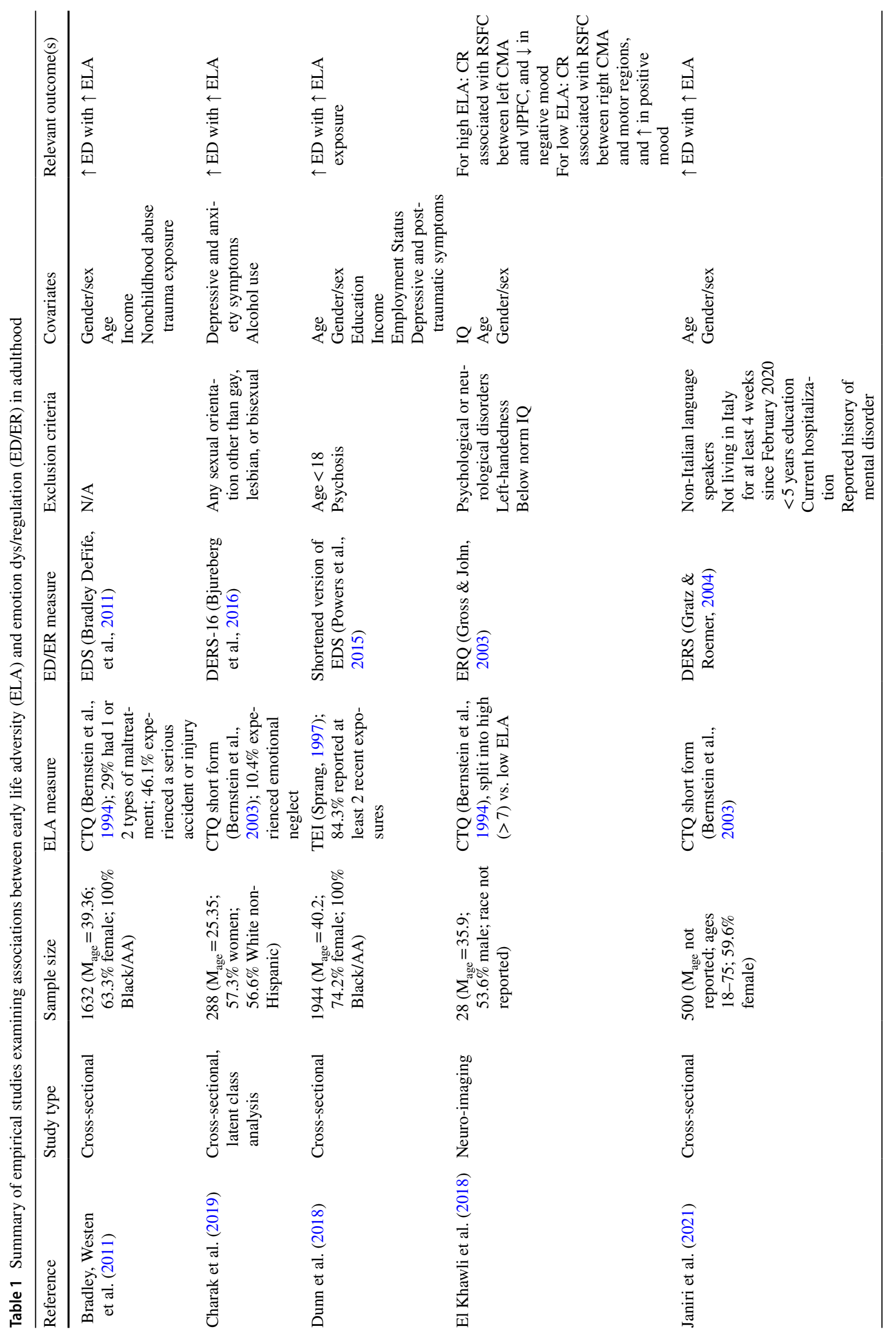




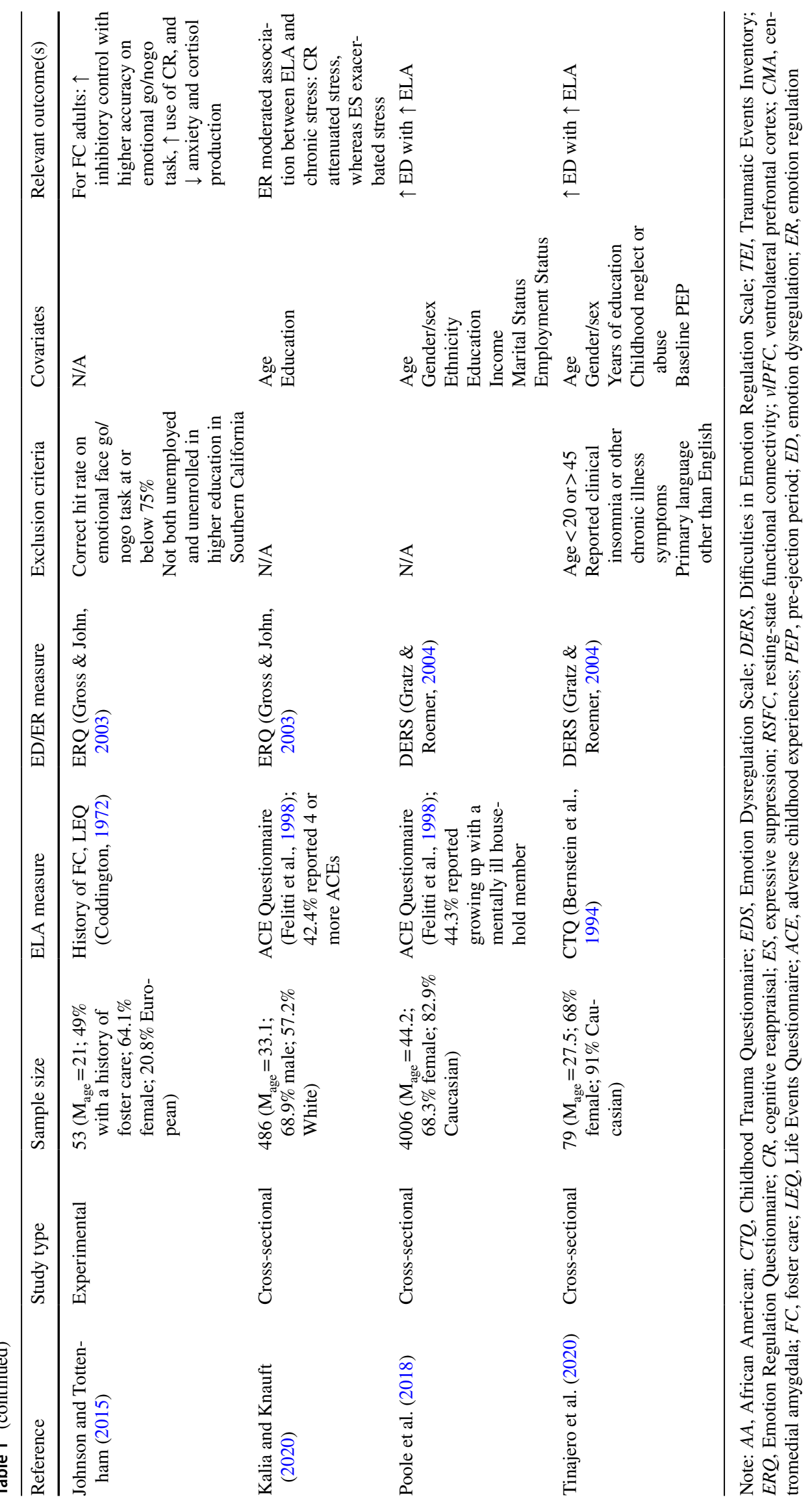


mental and physical health in the long term (Wadsworth, 2015). Compelling evidence suggests that neurobiological impairments, in addition to the environmental conditions that can predispose emotion dysregulation, may affect responding to emotional or threatening stimuli throughout the lifespan.

\section{Early Life Adversity and Cognitive Reappraisal}

Studies investigating associations between ELA and the specific emotion regulation strategy of cognitive reappraisal are also presented in Table 1 . These studies examined cognitive reappraisal as a moderator of various health indicators. A quasi-experimental study examined cognitive regulatory skills in adults with a history of foster care relative to a comparison group; greater levels of inhibitory control, which involves regulating undesired thoughts or actions, were associated with higher reported use of cognitive reappraisal and, in turn, decreased anxiety and cortisol production (Johnson \& Tottenham, 2015). The cross-sectional study previously discussed also found that self-reported reappraisal use attenuated associations between low to moderate reported ELA and perceived chronic stress (Kalia \& Knauft, 2020). Finally, El Khawli et al. (2018) examined resting-state functional connectivity (RSFC) between the left centromedial amygdala (CMA) and the left ventrolateral PFC; investigating functional networks at rest enables an understanding of the degree to which the coupling of these brain regions affects effortful emotion regulation (Kim et al., 2011). They found that the relatively negative RSFC between the left CMA and the left ventrolateral PFC was associated with higher selfreported reappraisal use among adults with a higher degree of reported childhood emotional abuse. The amygdalacentered RSFC was, in turn, associated with a dampening of negative mood (El Khawli et al., 2018). Taken together, these studies suggest beneficial associations between cognitive reappraisal use and several health indicators.

\section{Potential Factors Contributing to Associations Between Early Life Adversity and Cognitive Reappraisal Use in Adulthood}

Recent research has begun to identify neural processes underlying adaptive emotion regulation use in individuals who experienced ELA. Adults with a history of ELA who demonstrate effective emotion regulation abilities may develop larger hippocampal volumes, as well as larger volumes of the medial PFC, relative to adults with ELA who do not demonstrate resilient functioning (Moreno-López et al., 2020; Norbury et al., 2019). Additionally, adaptive emotion regulation abilities in adults who experienced ELA may be associated with enhanced functional connectivity between the PFC and the amygdala, to the extent that the PFC may inhibit amygdalar responding to emotional stimuli while increasing its habituation to stress (Moreno-López et al., 2020; Norbury et al., 2019; Taylor et al., 2011). Reappraisal appears to differentially affect amygdalacentered functional connectivity based on the degree of ELA, such that reappraisal may act as a protective factor for individuals with a history of ELA (El Khawli et al., 2018). It is worth testing whether amygdala hyperreactivity to emotional stimuli is protective for adults with a history of ELA because some research indicates that hyperreactivity may provide an enhanced ability to process emotional information, as compared to strategies that involve distraction or avoidance (Yamamoto et al., 2017). Current evidence suggests that individuals demonstrating resilient patterns of emotion regulation may manifest appropriate development of critical neural structures, as well as adaptive frontolimbic responding to emotional stimuli.

The ELA-specific factors presented in Fig. 1 may also help explain resilient outcomes in individuals with a history of ELA. Some of these factors relate to the perception of the adverse experience(s). For example, the controllability of early adverse experiences may modulate their effects on functional connectivity between the PFC and limbic structures, such that controllable stressors may promote resilience (see Cohodes et al., 2020; Feder et al., 2019). Additionally, a moderate amount of adversity may have a stress inoculation (or "toughening") effect, such that it leads to frequent reappraisal use, compared to experiencing either no adversity or an extreme amount of adversity (see Seery et al., 2010; Zhang \& Zhang, 2018). As such, Kalia and Knauft (2020) did not find moderating effects of reappraisal in individuals with very high ELA. The existence of contextual psychosocial factors is also clearly relevant. Meng et al. (2018) reviewed protective factors among adults with a history of ELA, which included not only individual (e.g., coping skills) but also familial (e.g., positive parenting) and societal (e.g., school safety) level factors. Furthermore, interventions such as the ACE [adverse childhood experience] Overcomers Program can teach effective emotion regulation skills, promote resilience, and improve mental and physical health problems (Cameron et al., 2018). Other emotion regulation enhancing interventions include hardiness training, mindfulness-based stress reduction (MBSR), and neurofeedback to improve frontolimbic connectivity (see Andersen et al., 2021; Feder et al., 2019). It is also possible that individuals switch to using healthier emotion regulation strategies throughout the lifespan (John \& Gross, 2004). Thus, the specifics of the early adverse experience(s), as well as any associated protective factors, can help explain how some individuals are able to habitually employ adaptive emotion regulation strategies despite enduring ELA. 


\section{Emotion Regulation and Inflammation}

\section{Emotion Dysregulation and Inflammation}

Table 2 presents all of the empirical studies examining associations between emotion dys/regulation and inflammatory markers in adults as demonstrated by our literature searches. Similar to Table 1, this table summarizes study type (e.g., prospective-longitudinal, cross-sectional, experimental), sample type (noting age, gender, race, and other demographic details if specified), exclusion criteria if used, and covariates used. Table 2 also summarizes the type of emotion dys/regulation measure utilized in the study (noting the age the measure was applied if applicable), and the specific inflammatory marker measured. Lastly, Table 2 summarizes the main results with regard to direction of the association between emotion dys/regulation and inflammation.

Two studies found that emotion dysregulation measured in childhood prospectively predicted higher plasma CRP levels in adults (Appleton et al., 2011, 2012). Greater self-reported use of expressive suppression in adulthood has also been linked to higher levels of blood-based proinflammatory markers cross-sectionally (Appleton et al., 2013; Ellis et al., 2019; Lopez et al., 2020). These studies suggest an association between self-reported emotion dysregulation and elevated inflammatory activity in adulthood. Seemingly in contrast, an experimental study did not find a relationship between baseline self-reported use of expressive suppression and nasal cytokines (e.g., IL-6 and IL-8) triggered in response to rhinovirus exposure (Brown et al., 2020). It is possible that self-reported use of habitual suppression does not link to experimentally induced inflammatory activity, but more studies would be needed before any distinctions between cross-sectional and experimental studies can be generalizable.

\section{Potential Factors Contributing to Associations Between Emotion Dysregulation and Inflammation}

Emotion dysregulation can lead to heightened physiological reactivity to stress and thus greater risk for chronic disease (see Miller et al., 2011; Taylor et al., 2011). For example, persistent use of maladaptive emotion regulation strategies (e.g., suppression) has been linked to increased amygdala activity, which, in turn, can activate a stress response leading to higher inflammation (see Black, 2002; Crowell et al., 2015; Gross, 2015). Further, adults with a history of childhood maltreatment have evidenced greater HPA axis activation and elevated levels of inflammatory markers relative to non-maltreated individuals (Danese \& McEwen, 2012). Ellis et al. (2019) found expressive suppression to contribute to inflammation through heightened perceived stress. Therefore, exacerbations of the psychological and physiological correlates of stress represent key potential pathways by which habitual emotion dysregulation can elevate inflammation in adulthood. Although not the focus of this proposed framework, emotion dysregulation may heighten inflammation through other pathways as well, such as via pain responding (e.g., see Edwards et al., 2008; Graham-Engeland et al., 2019).

\section{Cognitive Reappraisal and Inflammation}

Table 2 also presents studies examining associations between the specific emotion regulation strategy of cognitive reappraisal and inflammation in adulthood. Greater self-reported use of cognitive reappraisal in adulthood was associated with lower levels of blood-based inflammatory markers in two cross-sectional studies previously discussed (Appleton et al., 2013; Ellis et al., 2019). However, in contrast, one cross-sectional study previously discussed did not find an association between self-reported use of reappraisal and multiple proinflammatory markers in recently bereaved adults (Lopez et al., 2020). Together, these cross-sectional findings suggest that greater tendencies toward cognitive reappraisal can be linked with lower inflammatory markers. The relevant experimental literature is mixed, albeit scant: One experimental study previously discussed found that adults who reported more frequent use of cognitive reappraisal evidenced an attenuated local inflammatory response measured by nasal cytokines (e.g., IL-6 and IL-8) to rhinovirus exposure (Brown et al., 2020). However, an experimental neuroimaging study found a positive association between induced reappraisal efforts, measured by dorsal anterior cingulate cortex (dACC) activity, and higher plasma IL-6 levels (Gianaros et al., 2014). It is possible that active use of cognitive reappraisal in the moment could link to heightened inflammatory activity, at least in the short term, despite relatively consistent associations between self-reported use of reappraisal strategies and lower inflammatory markers. However, this existing literature is small, and there remain multiple untested possibilities; pre-existing individual differences in mental and physical health may relate to connections between emotion regulation, or activity in specific brain regions, and inflammatory processes.

\section{Potential Factors Contributing to Associations Between Cognitive Reappraisal Use and Inflammation}

There is some evidence that frequent use of cognitive reappraisal may reduce inflammation via changes in activity within and functional connectivity (e.g., mPFCamygdalar downregulation) among frontolimbic regions that support successful emotion regulation (Lopez et al., 2018; 


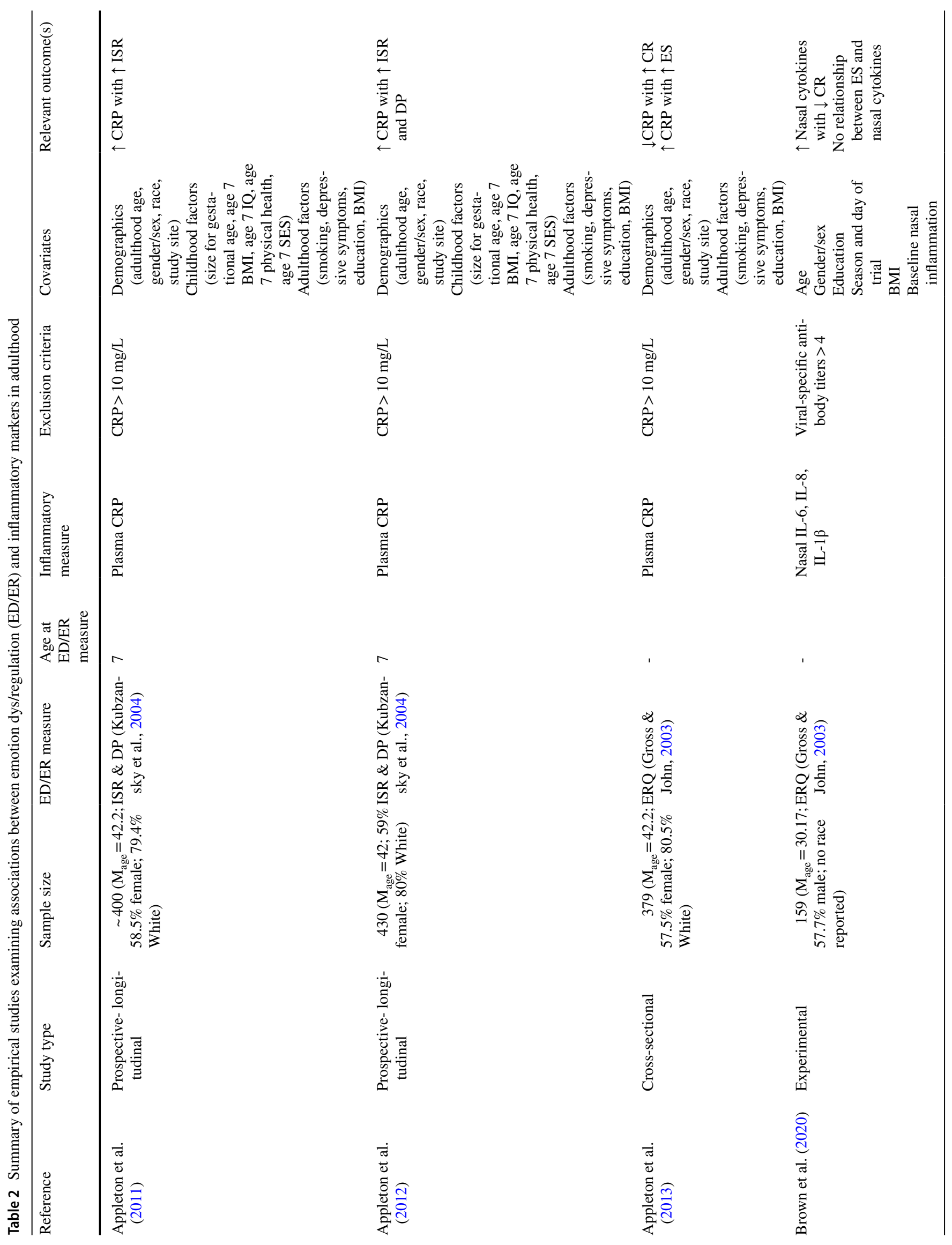




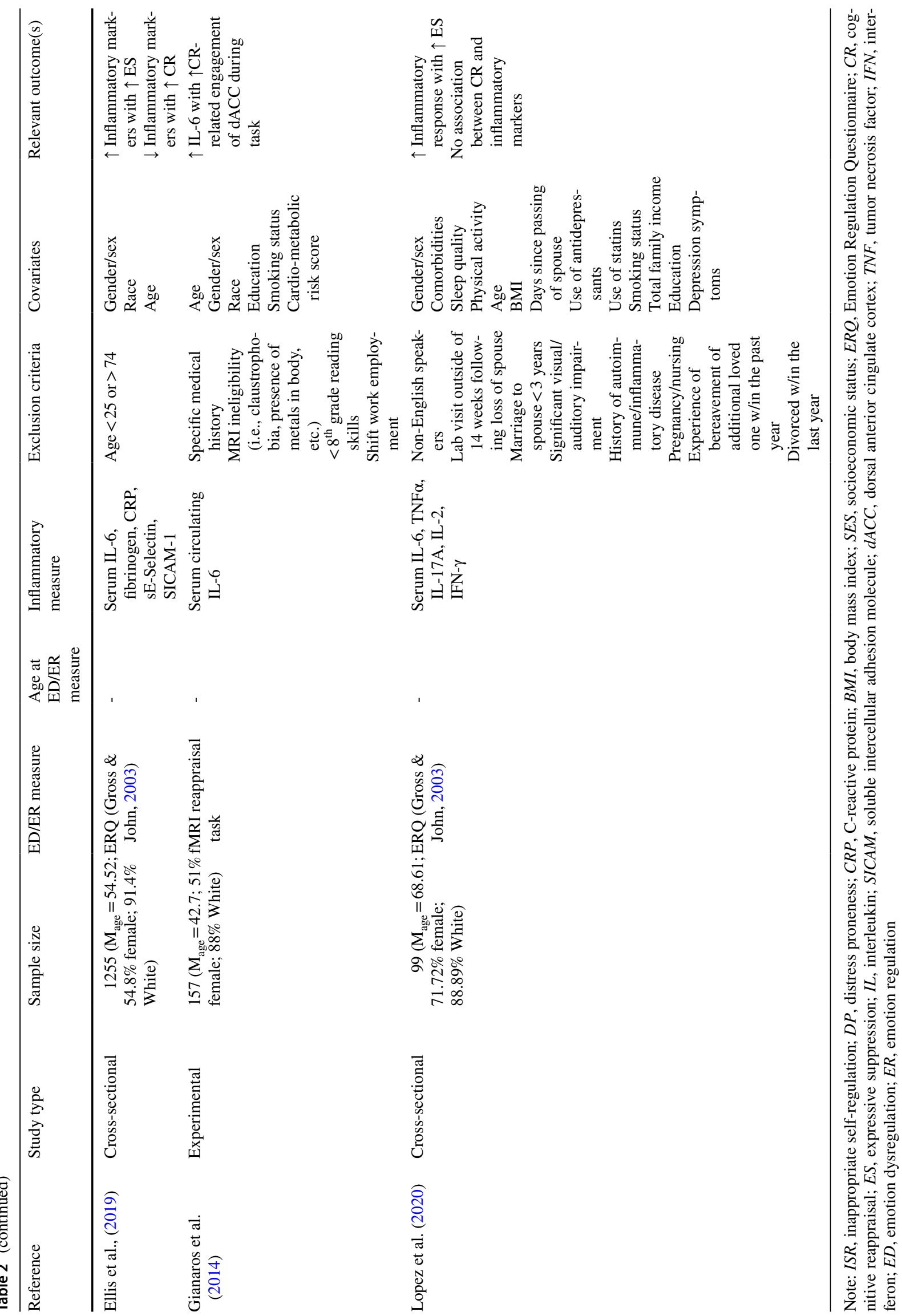


Moreno-Lopez et al., 2020). Further, cognitive reappraisal may reduce inflammation via decreasing negative emotions or increasing positive emotions (see DeSteno et al., 2013; Lopez et al., 2018; Tabibnia, 2020). It is also possible that adaptive emotion regulation strategies may have indirect effects through health promoting behaviors: For example, individuals who are better at managing emotions may experience better sleep, as well as utilize social support and limit substance use and unhealthy eating (see Appleton et al., 2013; Bergeman et al., 2020; Ellis et al., 2019). Connections between adaptive emotion regulation, health promoting behaviors, and physiological responding are worthy of further investigation.

Psychosocial interventions, such as cognitive-behavioral therapy (CBT) focused on stress and negative affect management (Mennin et al., 2013; Shields et al., 2020) and MBSR focused on training attention and fostering acceptance (see Chin et al., 2019; Lenaert et al., 2016; Lindsay et al., 2018, 2021), may also help decrease proinflammatory activity. For example, when utilized as an emotion regulation strategy, mindfulness training was linked to lower CRP in one study, and this association was stronger in vulnerable groups such as older adults and individuals with high body mass index (BMI; Villalba et al., 2019). Reappraising potentially threatening stimuli as manageable stressors may have downstream physiological consequences that result in decreased proinflammatory activity.

\section{Discussion}

The literature discussed in this conceptual framework supports emotion regulation as a potential driver of vulnerability or resilience to inflammation in adults with a history of early life adversity (e.g., maltreatment and neglect). ELA may program a proinflammatory state and disrupt the development and functional connectivity among brain areas critical for emotion regulation, namely the amygdala, prefrontal cortex (PFC), and hippocampus (see Chiang et al., 2015; Danese \& McEwen, 2012; Miller et al., 2011). Such neurobiological disruptions, as well as the psychosocial factors affecting the attainment of appropriate emotion regulation skills, can predispose threat sensitivity and heighten stress reactivity throughout adulthood and, in turn, increase proinflammatory activity (see Crowell et al., 2015; Repetti et al., 2002; Taylor et al., 2011). In contrast, the generally adaptive emotion regulation strategy of cognitive reappraisal may help prevent activation of the physiological stress response by reducing negative emotions and the perception of threat (DeSteno et al., 2013; Feder et al., 2019; Troy \& Mauss, 2011). Factors specific to adverse experiences (e.g., their intensity or controllability), as well as protective psychosocial factors and interventions, can promote adaptive emotion regulation in adults with a history of ELA (see Cameron et al., 2018; Cohodes et al., 2020; Meng et al., 2018; Seery et al., 2010). Consequently, cognitive reappraisal use has been associated with lower proinflammatory activity (e.g., see Appleton et al., 2013; Lopez et al., 2018). Despite the support for these plausible relationships, more empirical studies are needed to better understand the extent to which emotion regulation tendencies in adulthood can mediate and/or moderate associations between ELA and inflammation.

\section{Strengths of the Literature and Ideas for Future Research}

Many advancements in ELA research have occurred in the past few years. Novel studies have begun to differentiate the effects of ELA on the brain by its type, developmental timing, and duration (Cassiers et al., 2018; Cohodes et al., 2020; Dunn et al., 2018; Herzog et al., 2020; Teicher \& Samson, 2016). Further, recent research is categorizing ELA into the dimensions of harmful input/threat (e.g., abuse) or deprivation/inadequate input (e.g., neglect), with distinct effects on neural development and physiological stress responding (Hostinar et al., 2017; Kuhlman et al., 2017; Sheridan \& McLaughlin, 2014). New research has also compared cumulative risk scores of adverse experiences with single adversities, as well as retrospective and prospective measures of ELA, using latent class analysis (e.g., Lacey et al., 2020). Additionally, some of the recent studies examined here considered multiple inflammatory biomarkers in the same study (e.g., Ellis et al., 2019; Lopez et al., 2020), while others included biomarkers that have been less well examined in stress-focused research (Moore et al., 2020; Rasmussen et al., 2019). These conceptual and methodological advancements can be further tested using the model presented in Fig. 1 to enhance understanding of the role of emotion regulation in adaptive and maladaptive functioning following ELA.

Recent research has also better characterized neural processes among individuals demonstrating resilience to ELA (see El Khawli et al., 2018; Moreno-López et al., 2020; Norbury et al., 2019; Yamamoto et al., 2017). Additionally, investigations that consider the ELA-specific factors presented in Fig. 1 continue to improve our understanding of moderators that can lead to vulnerable or resilient outcomes following ELA. For example, novel studies suggest that the pubertal period can recalibrate differences in stress physiology in individuals with a history of ELA (e.g., King et al., 2017; Méndez Leal \& Silvers, 2020). Future research should integrate such findings to examine the extent to which emotion regulation tendencies can confer vulnerability or resilience to proinflammatory activity in adults with a history of ELA. 


\section{Limitations and Future Directions}

Despite the recent developments and exciting new research discussed above, there are several limitations that pervade most research examining resilience to ELA and thus limit which conclusions can be drawn currently. Prospective studies that consider baseline volumes of critical neural structures are needed to map trajectories of biological embedding to better characterize vulnerability or resilience to negative health outcomes following ELA (Heim et al., 2019; Ioannidis et al., 2020). Such mapping should also consider curvilinear models to examine possible toughening effects of ELA on particular mental and physical health outcomes (see Sapolsky, 2015; Seery et al., 2010). In addition, inconsistencies remain in defining resilience to ELA, examining resilient outcomes over time, and understanding the mechanisms by which psychosocial resources can contribute to adaptive functioning in adults with a history of ELA (Meng et al., 2018; Yoon et al., 2019). Although many resilience factors have been examined in the context of ELA (e.g., see Meng et al., 2018; Norbury et al., 2019; Yoon et al., 2019), it is not well understood how these factors affect neural and physiological processes and/ or interact with each other to promote adaptive emotion regulation. For example, it remains to be determined whether resilient individuals have innately larger hippocampus and/or $\mathrm{mPFC}$ volumes. Moreover, it is possible that individuals may demonstrate resilience to some stressors but not others (see Mathur et al., 2018; Rutter, 1987). The phenomenon of "skindeep resilience" exemplifies the importance of examining domain-specific resilience because it represents the possibility that seemingly protective psychological and behavioral factors (e.g., self-control) may take a toll on the body, with potentially worse downstream physical health outcomes for particular racial and socioeconomic groups (see Brody et al., 2016). As researchers continue to investigate resilience to ELA, it will be important to test a variety of pathways and examine both self-reported and objective indicators of health over time, as well as differences based on race, ethnicity, socioeconomic status (SES), and other demographic characteristics.

It is also important to avoid making causal claims solely from observational data (see Appleton et al., 2011; Danese, 2020; Kraemer et al., 2000). Most of the empirical studies discussed here were cross-sectional and had other important limitations. For example, a few studies measured emotion dysregulation in childhood only (Appleton et al., 2011, 2012), yet were included because of the limited empirical research examining associations between emotion regulation and inflammation. Similarly, many of the empirical studies discussed here relied on self-reported emotion regulation use at a single time point, which may not accurately capture actual variation in emotion regulation tendencies. Longitudinal studies that assess momentary variation in emotion regulation are needed to better understand the utility of cognitive reappraisal (e.g., see Southward \& Cheavens, 2020). It can be difficult for individuals to recall how they tend to respond to difficult circumstances, and such recollections can be influenced by memory bias and broad issues of self-perception, especially among individuals who experienced ELA and/or manifest psychological conditions (see Danese, 2020; Green et al., 2010). Studies that either assess naturally variable emotion regulation in real-time or experimental induction of emotion regulation strategies would help strengthen understanding of the precursors and consequences of emotion regulation. The only empirical study that manipulated emotion regulation found a positive association between cognitive reappraisal use and IL-6 levels (Gianaros et al., 2014). Additionally, Brown et al. (2020) did not find an association between self-reported expressive suppression use and inflammatory activity in response to a viral challenge, which underscores the importance of more experimental studies that can better elucidate the effects of emotion regulation on physical health (Ford \& Troy, 2019).

Although psychosocial therapies utilizing emotion regulation strategies such as CBT, expressive writing, and mindfulness meditation are promising (see Andersen et al., 2021; Cameron et al., 2018; Korotana et al., 2016; Mennin et al., 2013; Shields et al., 2020), it would be valuable for more research to examine specific interventional targets for adults with a history of ELA and proinflammatory phenotypes. More clinical trials should examine pharmacological therapies that target neurobiological and physical health outcomes (Feder et al., 2019; Korotana et al., 2016). Randomized controlled trials targeting emotion regulation strategies specifically would provide a better understanding of the causal relationships between emotion regulation and health-related outcomes. Further research investigating these psychosocial therapies in healthy and clinical populations, such as breast cancer survivors (Boyle et al., 2017; Dutcher et al., 2021) or patients with Generalized Anxiety Disorder (GAD; Hoge et al., 2017), will help broaden our understanding of mechanisms underlying resilience (see Aldao et al., 2010). Furthermore, preventive interventions beginning in childhood, such as those focused on parenting and family stability, may also help mitigate maladaptive psychological and physical functioning by optimizing brain plasticity (Feder et al., 2019; Heim \& Binder, 2012; Taylor et al., 2011). Variability exists in physical and psychological symptoms, even in healthy populations, and it is important to recognize that the same emotion regulation strategy might be more or less helpful based on an individual's history and social/environmental context.

Although much of the present review focused on cognitive reappraisal, given the strength of findings linking it with ELA and, separately, with inflammation, it represents only one emotion regulation strategy. Moreover, cognitive 
reappraisal may not always be the most adaptive across all situations. Reappraisal has been shown to be less effective when the situation eliciting the emotion is controllable or of high intensity (see Gross, 2015; Lopez et al., 2020; McRae, 2016; Troy et al., 2017). McRae and Gross (2020) provide a more extensive discussion of the moderators of cognitive reappraisal use. In addition to the situation-centered factors of controllability and intensity, individual-centered factors such as reappraisal skill and capacity may also influence the success of using reappraisal (Ford \& Troy, 2019). Even emotion regulation behaviors that are normally considered maladaptive, such as memory suppression, can be beneficial in healing from trauma (Mary et al., 2020). Further, recent research suggests the importance of polyregulation, which involves flexibly using multiple strategies to regulate emotions within an emotion episode (Ford et al., 2019). To this point, similar but operationally distinct strategies like acceptance and attention monitoring may be differentially effective at reducing inflammation (Manigault et al., 2018). It will be very valuable for future research to determine whether and how such strategies (and polyregulation) foster resilience and attenuate inflammatory responses, and how they differ in doing so from cognitive reappraisal. For example, reappraisal utilizes cognitive change to reframe the meaning of a thought and may have a greater impact on immediate subjective experiences; acceptance, an attitude of receptive and non-interfering openness to experiences and thoughts without changing them, may have a greater downstream impact on physiological responses to stress (Lindsay et al., 2018; Troy et al., 2018). Moreover, it will be important to consider different subtypes of cognitive reappraisal (see Shiota \& Levenson, 2012), in addition to reappraisal of stress and arousal states (e.g., see Brooks, 2014; Crum et al., 2020), which may also relate to ELA and inflammation. While the current literature generally supports a linkage between cognitive reappraisal and lower inflammation, further research will help elucidate the unique complexities of other emotion regulation strategies.

Alternative linkages between ELA, emotion regulation, and inflammation other than those emphasized here are possible. To test interactions between emotion regulation and person-level characteristics (Aldao, 2013), ELA could be tested as a moderator in the model presented in Fig. 1. For example, Appleton et al. (2012) found that low early SES exacerbated linkages between childhood emotional problems and high CRP levels in adulthood. Our proposed conceptual model could also be tested using low early SES as a predictor of emotion regulation tendencies and inflammation in adulthood. Additionally, inflammatory activity may help explain connections between ELA and emotion regulation, as it is well established that heightened proinflammatory activity can drive changes in mood and well-being (Maier \& Watkins, 1998; Raison et al., 2006). Further, bidirectional communication between the brain and immune system may also affect vulnerability or resilience to the sequelae of ELA (see Kraynak et al., 2019; Nusslock et al., 2019; Redlich et al., 2015; Shields et al., 2017). Gianaros et al. (2014) may have found greater inflammatory activity following reappraisal efforts due to such bidirectional associations: An increase in IL-6 levels may have heightened negative affect, which, in turn, could have been more challenging for participants to regulate. Similarly, grief among recently bereaved spouses may have weakened any beneficial associations between cognitive reappraisal use and immune functioning in the study by Lopez et al. (2020). Testing the effects of inflammation on the central nervous system will improve our knowledge of the possible mechanisms by which ELA can affect health outcomes. It will also be important to examine lifestyle factors that can influence all of the aforementioned relationships between ELA, emotion regulation, and inflammation, such as health behaviors and perceived stress, including distress linked to the current COVID-19 pandemic (e.g., see Baldwin \& Danese, 2019; Duffy et al., 2018; Salari et al., 2020).

\section{Conclusion}

Adversity experienced in childhood or adolescence can profoundly increase risk for mental and physical health conditions throughout the lifespan (Herzog \& Schmahl, 2018; Suglia et al., 2018). We presented a theoretical model that considers emotion regulation as a potential driver of either vulnerability to inflammation (e.g., via emotion dysregulation) or resilience to inflammation (e.g., via cognitive reappraisal) in adults with a history of ELA. Although the body of research examining resilience following ELA is more limited than that showing negative health consequences, evidence suggests that individuals who have experienced ELA are not necessarily destined to a life of chronic mental and physical health problems. Important research is examining ways to prevent ELA given that it is a largely avoidable risk factor for many negative health outcomes (Bellis et al., 2019; van IJzendoorn et al., 2020). Meanwhile, as emotion regulation skills represent malleable targets to increase resilience to the sequelae of ELA (e.g., Cameron et al., 2018), future studies should continue to untangle the specific factors and processes that mitigate pathways of vulnerability and facilitate positive adaptation. Importantly, the burden for achieving resilience to the sequelae of ELA should not just be on the individual: A better understanding of the role of emotion regulation in the pathway between ELA and inflammation may uncover novel targets for prevention and intervention not only at the individual level, but even more broadly at the community level (e.g., see Ellis \& Dietz, 2017).

Note: IL-6, interleukin-6; CRP, C-reactive protein. 


\section{Declarations}

Competing Interests The authors declare no competing interests.

\section{References}

\section{*References marked with an asterisk indicate studies included in the review, as well as in Tables 1 and 2.}

Agorastos, A., Pervanidou, P., Chrousos, G. P., \& Baker, D. G. (2019). Developmental trajectories of early life stress and trauma: A narrative review on neurobiological aspects beyond stress system dysregulation [Review]. Frontiers in Psychiatry, 10(118). https:// doi.org/10.3389/fpsyt.2019.00118

Aldao, A. (2013). The future of emotion regulation research: Capturing context. Perspectives on Psychological Science, 8(2), 155-172. https://doi.org/10.1177/1745691612459518

Aldao, A., Nolen-Hoeksema, S., \& Schweizer, S. (2010). Emotionregulation strategies across psychopathology: A meta-analytic review. Clinical Psychology Review, 30(2), 217-237. https://doi. org/10.1016/j.cpr.2009.11.004

Andersen, E., Geiger, P., Schiller, C., Bluth, K., Watkins, L., Zhang, Y., Xia, K., Tauseef, H., Leserman, J., Girdler, S., \& Gaylord, S. (2021). Effects of Mindfulness-Based Stress Reduction on experimental pain sensitivity and cortisol responses in women with early life abuse: A randomized controlled trial. Psychosomatic Medicine, 83(6), 515-527. https://doi.org/10.1097/PSY. 0000000000000889

*Appleton, A. A., Buka, S. L., Loucks, E. B., Gilman, S. E., \& Kubzansky, L. D. (2013). Divergent associations of adaptive and maladaptive emotion regulation strategies with inflammation. Health Psychology, 32(7), 748-756. https://doi.org/10.1037/a0030068

*Appleton, A. A., Buka, S. L., McCormick, M. C., Koenen, K. C., Loucks, E. B., Gilman, S. E., \& Kubzansky, L. D. (2011). Emotional functioning at age 7 years is associated with $\mathrm{C}$-reactive protein in middle adulthood. Psychosomatic Medicine, 73(4), 295-303. https://doi.org/10.1097/PSY.0b013e31821534f6

*Appleton, A. A., Buka, S. L., McCormick, M. C., Koenen, K. C., Loucks, E. B., \& Kubzansky, L. D. (2012). The association between childhood emotional functioning and adulthood inflammation is modified by early-life socioeconomic status. Health Psychology, 31(4), 413-422. https://doi.org/10.1037/a0027300

Baldwin, J. R., \& Danese, A. (2019). Pathways from childhood maltreatment to cardiometabolic disease: A research review. Adoption \& Fostering, 43(3), 329-339. https://doi.org/10.1177/03085 75919856175

Baumeister, D., Akhtar, R., Ciufolini, S., Pariante, C. M., \& Mondelli, V. (2016). Childhood trauma and adulthood inflammation: A meta-analysis of peripheral C-reactive protein, interleukin- 6 and tumour necrosis factor- $\alpha$. Molecular Psychiatry, 21(5), 642-649. https://doi.org/10.1038/mp.2015.67

Bellis, M. A., Hughes, K., Ford, K., Ramos Rodriguez, G., Sethi, D., \& Passmore, J. (2019). Life course health consequences and associated annual costs of adverse childhood experiences across Europe and North America: A systematic review and meta-analysis. The Lancet Public Health, 4(10), e517-e528. https://doi.org/10.1016/ s2468-2667(19)30145-8

Bergeman, C. S., Blaxton, J., \& Joiner, R. (2020). Dynamic systems, contextual influences, and multiple timescales: Emotion regulation as a resilience resource. The Gerontologist. https:// doi.org/10.1093/geront/gnaa046

Bernstein, D. P., Fink, L., Handelsman, L., Foote, J., Lovejoy, M., Wenzel, K., Sapareto, E., \& Ruggiero, J. (1994). Initial reliability and validity of a new retrospective measure of child abuse and neglect. American Journal of Psychiatry, 151(8), 1132-1136. https://doi.org/10.1176/ajp.151.8.1132

Bernstein, D. P., Stein, J. A., Newcomb, M. D., Walker, E., Pogge, D., Ahluvalia, T., ...Zule, W. (2003). Development and validation of a brief screening version of the Childhood Trauma Questionnaire. Child Abuse \& Neglect, 27(2), 169-190. https:// doi.org/10.1016/S0145-2134(02)00541-0

Black, P. H. (2002). Stress and the inflammatory response: A review of neurogenic inflammation. Brain, Behavior, and Immunity, 16(6), 622-653. https://doi.org/10.1016/s0889-1591(02) 00021-1

Bjureberg, J., Ljótsson, B., Tull, M. T., Hedman, E., Sahlin, H., Lundh, L. G., ... Gratz, K. L. (2016). Development and validation of a brief version of the Difficulties in Emotion Regulation Scale: The DERS-16. Journal of Psychopathology and Behavioral Assessment, 38(2), 284-296. https://doi.org/10.1007/ s10862-015-9514-x

Bonanno, G. A., Papa, A., Lalande, K., Westphal, M., \& Coifman, K. (2004). The importance of being flexible: The ability to both enhance and suppress emotional expression predicts long-term adjustment. Psychological Science, 15(7), 482-487. https://doi. org/10.1111/j.0956-7976.2004.00705.x

Boyle, C. C., Stanton, A. L., Ganz, P. A., Crespi, C. M., \& Bower, J. E. (2017). Improvements in emotion regulation following mindfulness meditation: Effects on depressive symptoms and perceived stress in younger breast cancer survivors. Journal of Consulting and Clinical Psychology, 85(4), 397-402. https://doi.org/10. 1037/ccp0000186

Bradley, B., DeFife, J. A., Guarnaccia, C., Phifer, J., Fani, N., Ressler, K. J., \& Westen, D. (2011a). Emotion dysregulation and negative affect: Association with psychiatric symptoms. The Journal of Clinical Psychiatry, 72(5), 685-691. https://doi.org/10.4088/ JCP.10m06409blu

*Bradley, B., Westen, D., Mercer, K. B., Binder, E. B., Jovanovic, T., Crain, D., Wingo, A., \& Heim, C. (2011b). Association between childhood maltreatment and adult emotional dysregulation in a low-income, urban, African American sample: Moderation by oxytocin receptor gene. Development and Psychopathology, 23(2), 439-452. https://doi.org/10.1017/S0954579411000162

Brody, G. H., Yu, T., \& Beach, S. R. (2016). Resilience to adversity and the early origins of disease. Development and Psychopathology, 28(4pt2), 1347-1365. https://doi.org/10.1017/S095457941 6000894

Brooks, A. (2014). Get excited: Reappraising pre-performance anxiety as excitement. Journal of Experimental Psychology General, 143(3), 1144-1158. https://doi.org/10.1037/a0035325

*Brown, R. L., Shahane, A. D., Chen, M. A., \& Fagundes, C. P. (2020). Cognitive reappraisal and nasal cytokine production following experimental rhinovirus infection. Brain, Behavior, \& Immunity, 1, 100012. https://doi.org/10.1016/j.bbih.2019.100012

Cameron, L. D., Carroll, P., \& Hamilton, W. K. (2018). Evaluation of an intervention promoting emotion regulation skills for adults with persisting distress due to adverse childhood experiences. Child Abuse \& Neglect, 79, 423-433. https://doi.org/10.1016/j. chiabu.2018.03.002

Cassiers, L. L. M., Sabbe, B. G. C., Schmaal, L., Veltman, D. J., Penninx, B. W. J. H., \& Van Den Eede, F. (2018). Structural and functional brain abnormalities associated with exposure to different childhood trauma subtypes: A systematic review of neuroimaging findings [Systematic Review]. Frontiers in Psychiatry, 9(329). https://doi.org/10.3389/fpsyt.2018.00329 
*Charak, R., Villarreal, L., Schmitz, R. M., Hirai, M., \& Ford, J. D. (2019). Patterns of childhood maltreatment and intimate partner violence, emotion dysregulation, and mental health symptoms among lesbian, gay, and bisexual emerging adults: A three-step latent class approach. Child Abuse \& Neglect, 89, 99-110. https://doi.org/10.1016/j.chiabu.2019.01.007

Chiang, J. J., Taylor, S. E., \& Bower, J. E. (2015). Early adversity, neural development, and inflammation. Developmental Psychobiology, 57(8), 887-907. https://doi.org/10.1002/dev.21329

Chin, B., Lindsay, E. K., Greco, C. M., Brown, K. W., Smyth, J. M., Wright, A. G. C., \& Creswell, J. D. (2019). Psychological mechanisms driving stress resilience in mindfulness training: A randomized controlled trial. Health Psychology, 38(8), 759-768. https://doi.org/10.1037/hea0000763

Cicchetti, D., \& Rogosch, F. A. (2009). Adaptive coping under conditions of extreme stress: Multilevel influences on the determinants of resilience in maltreated children. New Directions for Child and Adolescent Development, 2009(124), 47-59. https:// doi.org/10.1002/cd.242

Coddington, R. D. (1972). The significance of life events as etiologic factors in the diseases of children. II. A study of a normal population. Journal of Psychosomatic Research, 16(3), 205-213. https://doi.org/10.1016/0022-3999(72)90045-1

Coelho, R., Viola, T. W., Walss-Bass, C., Brietzke, E., \& GrassiOliveira, R. (2014). Childhood maltreatment and inflammatory markers: A systematic review. Acta Psychiatrica Scandinavica, 129(3), 180-192. https://doi.org/10.1111/acps.12217

Cohodes, E. M., Kitt, E. R., Baskin-Sommers, A., \& Gee, D. G. (2020). Influences of early-life stress on frontolimbic circuitry: Harnessing a dimensional approach to elucidate the effects of heterogeneity in stress exposure. Developmental Psychobiology. https://doi.org/10.1002/dev.21969

Crowell, S. E., Puzia, M. E., \& Yaptangco, M. (2015). The ontogeny of chronic distress: Emotion dysregulation across the life span and its implications for psychological and physical health. Current Opinion in Psychology, 3, 91-99. https://doi.org/10. 1016/j.copsyc.2015.03.023

Crum, A., Jamieson, J., \& Akinola, M. (2020). Optimizing stress: An integrated Intervention for regulating stress responses. Emotion (Washington, D.C.), 20(1), 120-125. https://doi.org/10. $1037 / \mathrm{emo} 0000670$

Danese, A. (2020). Annual Research Review: Rethinking childhood trauma-new research directions for measurement, study design and analytical strategies. Journal of Child Psychology and Psychiatry, 61(3), 236-250. https://doi.org/10.1111/jcpp.13160

Danese, A., \& McEwen, B. S. (2012). Adverse childhood experiences, allostasis, allostatic load, and age-related disease. Physiology \& Behavior, 106(1), 29-39. https://doi.org/10.1016/j. physbeh.2011.08.019

Deighton, S., Neville, A., Pusch, D., \& Dobson, K. (2018). Biomarkers of adverse childhood experiences: A scoping review. Psychiatry Research, 269, 719-732. https://doi.org/10.1016/j. psychres.2018.08.097

DeSteno, D., Gross, J. J., \& Kubzansky, L. (2013). Affective science and health: The importance of emotion and emotion regulation. Health Psychology, 32(5), 474-486. https://doi.org/10. 1037/a0030259

Duffy, K. A., McLaughlin, K. A., \& Green, P. A. (2018). Early life adversity and health-risk behaviors: Proposed psychological and neural mechanisms. Annals of the New York Academy of Sciences, 1428(1), 151-169. https://doi.org/10.1111/nyas. 13928

Dunkel-Schetter, C., \& Dolbier, C. (2011). Resilience in the context of chronic stress and health in adults. Social and Personality Psychology Compass, 5(9), 634-652. https://doi.org/10.1111/j. 1751-9004.2011.00379.x
*Dunn, E. C., Nishimi, K., Gomez, S. H., Powers, A., \& Bradley, B. (2018). Developmental timing of trauma exposure and emotion dysregulation in adulthood: Are there sensitive periods when trauma is most harmful? Journal of Affective Disorders, 227, 869-877. https://doi.org/10.1016/j.jad.2017. 10.045

Dutcher, J. M., Boyle, C. C., Eisenberger, N. I., Cole, S. W., \& Bower, J. E. (2021). Neural responses to threat and reward and changes in inflammation following a mindfulness intervention. Psychoneuroendocrinology, 125. https://doi.org/10.1016/j.psyneuen. 2020.105114

Dvir, Y., Ford, J. D., Hill, M., \& Frazier, J. A. (2014). Childhood maltreatment, emotional dysregulation, and psychiatric comorbidities. Harvard Review of Psychiatry, 22(3), 149-161. https://doi. org/10.1097/HRP.0000000000000014

Edwards, R. R., Kronfli, T., Haythornthwaite, J. A., Smith, M. T., McGuire, L., \& Page, G. G. (2008). Association of catastrophizing with interleukin-6 responses to acute pain. Pain, 140(1), 135-144. https://doi.org/10.1016/j.pain.2008.07.024

*El Khawli, E., Fan, Y., Aust, S., Wirth, K., Bönke, L., Stevense, A., Herrera, A., Metz, S., Loayza, A., Bajbouj, M., \& Grimm, S. (2018). Early-life stress modulates neural networks associated with habitual use of reappraisal. Behavioural Brain Research, 337, 210-217. https://doi.org/10.1016/j.bbr.2017.09.018

*Ellis, E. M., Prather, A. A., Grenen, E. G., \& Ferrer, R. A. (2019). Direct and indirect associations of cognitive reappraisal and suppression with disease biomarkers. Psychology \& Health, 34(3), 336-354. https://doi.org/10.1080/08870446.2018.15293 13

Ellis, W., \& Dietz, W. (2017). A new framework for addressing adverse childhood and community experiences: The Building Community Resilience Model. Academic Pediatrics, 17(7), S86-S93. https://doi.org/10.1016/j.acap.2016.12.011

Fagundes, C. P., Glaser, R., \& Kiecolt-Glaser, J. K. (2013). Stressful early life experiences and immune dysregulation across the lifespan. Brain, Behavior, and Immunity, 27(1), 8-12. https://doi.org/ 10.1016/j.bbi.2012.06.014

Fagundes, C. P., \& Way, B. (2014). Early-life stress and adult inflammation. Current Directions in Psychological Science, 23(4), 277-283. https://doi.org/10.1177/0963721414535603

Feder, A., Fred-Torres, S., Southwick, S. M., \& Charney, D. S. (2019). The biology of human resilience: Opportunities for enhancing resilience across the life span. Biological Psychiatry, 86(6), 443-453. https://doi.org/10.1016/j.biopsych.2019. 07.012

Felitti, V. J., Anda, R. F., Nordenberg, D., Williamson, D. F., Spitz, A. M., Edwards, V., Koss, M. P., \& Marks, J. S. (1998). Relationship of childhood abuse and household dysfunction to many of the leading causes of death in adults: The Adverse Childhood Experiences (ACE) Study. American Journal of Preventive Medicine, 14(4), 245-258.

Ferrucci, L., \& Fabbri, E. (2018). Inflammageing: Chronic inflammation in ageing, cardiovascular disease, and frailty. Nature Reviews Cardiology, 15(9), 505-522. https://doi.org/10.1038/ s41569-018-0064-2

Ford, B. Q., Gross, J. J., \& Gruber, J. (2019). Broadening our field of view: The role of emotion polyregulation. Emotion Review, 11(3), 197-208. https://doi.org/10.1177/1754073919850314

Ford, B. Q., \& Troy, A. S. (2019). Reappraisal reconsidered: A closer look at the costs of an acclaimed emotion-regulation strategy. Current Directions in Psychological Science, 28(2), 195-203. https://doi.org/10.1177/0963721419827526

Ganguly, P., \& Brenhouse, H. C. (2015). Broken or maladaptive? Altered trajectories in neuroinflammation and behavior after early life adversity. Developmental Cognitive Neuroscience, 11, 18-30. https://doi.org/10.1016/j.den.2014.07.001 
*Gianaros, P. J., Marsland, A. L., Kuan, D. C., Schirda, B. L., Jennings, J. R., Sheu, L. K., Hariri, A. R., Gross, J. J., \& Manuck, S. B. (2014). An inflammatory pathway links atherosclerotic cardiovascular disease risk to neural activity evoked by the cognitive regulation of emotion. Biological Psychiatry, 75(9), 738-745. https://doi.org/10.1016/j.biopsych.2013.10.012

Glaser, R., \& Kiecolt-Glaser, J. K. (2005). Stress-induced immune dysfunction: Implications for health. Nature Reviews, 5, 243-251. https://doi.org/10.1038/nri1571

Gouin, J.-P., Caldwell, W., Woods, R., \& Malarkey, W. B. (2017). Resilience resources moderate the association of adverse childhood experiences with adulthood inflammation. Annals of Behavioral Medicine, 51(5), 782-786. https://doi.org/10.1007/ s12160-017-9891-3

Graham-Engeland, J. E., Song, S., Mathur, A., Wagstaff, D. A., Klein, L. C., Whetzel, C., \& Ayoub, W. T. (2019). Emotional state can affect inflammatory responses to pain among rheumatoid arthritis patients: Preliminary findings. Psychological Reports, 122(6), 2026-2049. https://doi.org/10.1177/0033294118796655

Gratz, K. L., \& Roemer, L. (2004). Multidimensional assessment of emotion regulation and dysregulation: Development, factor structure, and initial validation of the Difficulties in Emotion Regulation Scale. Journal of Psychopathology and Behavioral Assessment, 26(1), 41-54. https://doi.org/10.1023/B:JOBA. 0000007455.08539 .94

Green, J. G., McLaughlin, K. A., Berglund, P. A., Gruber, M. J., Sampson, N. A., Zaslavsky, A. M., \& Kessler, R. C. (2010). Childhood adversities and adult psychiatric disorders in the national comorbidity survey replication I: Associations with first onset of DSM-IV disorders. Archives of General Psychiatry, 67(2), 113-123. https://doi.org/10.1001/archgenpsychiatry.2009.186

Gross, J. J. (2015). Emotion regulation: Current status and future prospects. Psychological Inquiry, 26(1), 1-26. https://doi.org/ 10.1080/1047840x.2014.940781

Gross, J. J., \& John, O. P. (2003). Individual differences in two emotion regulation processes: Implications for affect, relationships, and well-being. Journal of Personality and Social Psychology, $85(2), 348-362$.

Gross, J. J., \& Thompson, R. A. (2007). Emotion regulation: Conceptual foundations. In J. J. Gross (Ed.), Handbook of emotion regulation (pp. 3-24). Guilford Press.

Heim, C., \& Binder, E. B. (2012). Current research trends in early life stress and depression: Review of human studies on sensitive periods, gene-environment interactions, and epigenetics. Experimental Neurology, 233(1), 102-111. https://doi.org/10.1016/j. expneurol.2011.10.032

Heim, C. M., Entringer, S., \& Buss, C. (2019). Translating basic research knowledge on the biological embedding of early-life stress into novel approaches for the developmental programming of lifelong health. Psychoneuroendocrinology, 105, 123-137. https://doi.org/10.1016/j.psyneuen.2018.12.011

Hein, T. C., \& Monk, C. S. (2017). Research Review: Neural response to threat in children, adolescents, and adults after child maltreatment - A quantitative meta-analysis. Journal of Child Psychology and Psychiatry, 58(3), 222-230. https://doi.org/10.1111/ jcpp. 12651

Herzberg, M. P., \& Gunnar, M. R. (2020). Early life stress and brain function: Activity and connectivity associated with processing emotion and reward. NeuroImage, 209, 116493. https://doi.org/ 10.1016/j.neuroimage.2019.116493

Herzog, J. I., \& Schmahl, C. (2018). Adverse childhood experiences and the consequences on neurobiological, psychosocial, and somatic conditions across the lifespan [Review]. Frontiers in Psychiatry, 9(420). https://doi.org/10.3389/fpsyt.2018.00420

Herzog, J. I., Thome, J., Demirakca, T., Koppe, G., Ende, G., Lis, S., Rausch, S., Priebe, K., Muller-Engelmann, M., Steil, R., Bohus,
M., \& Schmahl, C. (2020). Influence of severity of type and timing of retrospectively reported childhood maltreatment on female amygdala and hippocampal volume. Scientific Reports, 10(1), 1903. https://doi.org/10.1038/s41598-020-57490-0

Hoge, E. A., Bui, E., Palitz, S. A., Schwarz, N. R., Owens, M. E., Johnston, J. M., Pollack, M. H., \& Simon, N. M. (2017). The effects of mindfulness meditation training on biological acute stress responses in generalized anxiety disorder. Psychiatry Research, 262, 328-332. https://doi.org/10.1016/j.psychres.2017.01.006

Hostinar, C. E., Nusslock, R., \& Miller, G. E. (2017). Future directions in the study of early-life stress and physical and emotional health: Implications of the neuroimmune network hypothesis. Journal of Clinical Child \& Adolescent Psychology, 47(1), 142-156. https:// doi.org/10.1080/15374416.2016.1266647

Hu, T., Zhang, D., Wang, J., Mistry, R., Ran, G., \& Wang, X. (2014). Relation between emotion regulation and mental health: A metaanalysis review. Psychological Reports, 114(2), 341-362. https:// doi.org/10.2466/03.20.PR0.114k22w4

Ioannidis, K., Askelund, A. D., Kievit, R. A., \& van Harmelen, A. L. (2020). The complex neurobiology of resilient functioning after childhood maltreatment. BMC Medicine, 18(1), 1-16. https://doi. org/10.1186/s12916-020-1490-7

Irwin, M. R., \& Rothermundt, M. (2012). Clinical psychoneuroimmunology. Handbook of Clinical Neurology, 106, 211-225. https:// doi.org/10.1016/B978-0-444-52002-9.00012-7

*Janiri, D., Moccia, L., Dattoli, L., Pepe, M., Molinaro, M., De Martin, V., Chieffo, D., Di Nicola, M., Fiorillo, A., Janiri, L., \& Sani, G. (2021). Emotional dysregulation mediates the impact of childhood trauma on psychological distress: First Italian data during the early phase of COVID-19 outbreak. Australian \& New Zealand Journal of Psychiatry. https://doi.org/10.1177/0004867421 998802

John, O. P., \& Gross, J. J. (2004). Healthy and unhealthy emotion regulation: Personality processes, individual differences, and life span development. Journal of Personality, 72(6), 1301-1334.

*Johnson, A. J., \& Tottenham, N. (2015). Regulatory skill as a resilience factor for adults with a history of foster care: A pilot study. Developmental Psychobiology, 57(1), 1-16. https://doi.org/10. 1002/dev.21227

*Kalia, V., \& Knauft, K. (2020). Emotion regulation strategies modulate the effect of adverse childhood experiences on perceived chronic stress with implications for cognitive flexibility. PLoS ONE, 15(6), e0235412. https://doi.org/10.1371/journal.pone. 0235412

Kim, M. J., Loucks, R. A., Palmer, A. L., Brown, A. C., Solomon, K. M., Marchante, A. N., \& Whalen, P. J. (2011). The structural and functional connectivity of the amygdala: From normal emotion to pathological anxiety. Behavioural Brain Research, 223(2), 403-410. https://doi.org/10.1016/j.bbr.2011.04.025

King, L. S., Colich, N. L., LeMoult, J., Humphreys, K. L., Ordaz, S. J., Price, A. N., \& Gotlib, I. H. (2017). The impact of the severity of early life stress on diurnal cortisol: The role of puberty. Psychoneuroendocrinology, 77, 68-74. https://doi.org/10.1016/j. psyneuen.2016.11.024

Korotana, L. M., Dobson, K. S., Pusch, D., \& Josephson, T. (2016). A review of primary care interventions to improve health outcomes in adult survivors of adverse childhood experiences. Clinical Psychology Review, 46, 59-90. https://doi.org/10.1016/j.cpr. 2016.04.007

Kraemer, H. C., Yesavage, J. A., Taylor, J. L., \& Kupfer, D. (2000). How can we learn about developmental processes from crosssectional studies, or can we? American Journal of Psychiatry, 157(2), 163-171.

Kraynak, T. E., Marsland, A. L., Hanson, J. L., \& Gianaros, P. J. (2019). Retrospectively reported childhood physical abuse, systemic inflammation, and resting corticolimbic connectivity 
in midlife adults. Brain, Behavior, and Immunity, 82, 203-213. https://doi.org/10.1016/j.bbi.2019.08.186

Krugers, H. J., Arp, J. M., Xiong, H., Kanatsou, S., Lesuis, S. L., Korosi, A., Joels, M., \& Lucassen, P. J. (2016). Early life adversity: Lasting consequences for emotional learning. Neurobiology of Stress, 1-8. https://doi.org/10.1016/j.ynstr.2016.11.005

Kubzansky, L. D., Martin, L. T., \& Buka, S. L. (2004). Early manifestations of personality and adult emotional functioning. Emotion, 4(4), 364. https://doi.org/10.1037/1528-3542.4.4.364

Kuhlman, K. R., Chiang, J. J., Horn, S., \& Bower, J. E. (2017). Developmental psychoneuroendocrine and psychoneuroimmune pathways from childhood adversity to disease. Neuroscience and Biobehavioral Reviews, 80, 166-184. https://doi.org/10.1016/j. neubiorev.2017.05.020

Lacey, R. E., Pinto Pereira, S. M., Li, L., \& Danese, A. (2020). Adverse childhood experiences and adult inflammation: Single adversity, cumulative risk and latent class approaches. Brain, Behavior, and Immunity, 87, 820-830. https://doi.org/10.1016/j.bbi.2020. 03.017

Lenaert, B., Barry, T. J., SChruers, K., Vervliet, B., \& Hermans, D. (2016). Emotional attentional control predicts changes in diurnal cortisol secretion following exposure to a prolonged psychosocial stressor. Psychoneuroendocrinology, 63, 291-295. https:// doi.org/10.1016/j.psyneuen.2015.10.013

Li J.C., Danese A. (2018) Biological embedding of child maltreatment through inflammation. In: Noll J., Shalev I. (eds), The biology of early life stress. Child Maltreatment Solutions Network. Springer, Cham. https://doi.org/10.1007/978-3-319-72589-5_1

Lindsay, E. K., Creswell, J. D., Harrison, J. S., Greco, C. M., Dutcher, J. M., Lipitz, S., Walsh, C. W., Wright, A. G. C., Brown, K. W., \& Marsland, A. L. (2021). Mindfulness-Based Stress Reduction buffers glucocorticoid resistance among older adults: A randomized controlled trial. Psychosomatic Medicine, 83(6), 641649. https://doi.org/10.1097/PSY.0000000000000928

Lindsay, E. K., Young, S., Smyth, J. M., Brown, K. W., \& Creswell, J. D. (2018). Acceptance lowers stress reactivity: Dismantling mindfulness training in a randomized controlled trial. Psychoneuroendocrinology, 87, 63-73. https://doi.org/10.1016/j.psyne uen.2017.09.015

*Lopez, R. B., Brown, R. L., Wu, E. L., Murdock, K. W., Denny, B. T., Heijnen, C., \& Fagundes, C. (2020). Emotion regulation and immune functioning during grief: Testing the role of expressive suppression and cognitive reappraisal in inflammation among recently bereaved spouses. Psychosomatic Medicine, 82(1), 2-9. https://doi.org/10.1097/PSY.0000000000000755

Lopez, R. B., Denny, B. T., \& Fagundes, C. P. (2018). Neural mechanisms of emotion regulation and their role in endocrine and immune functioning: A review with implications for treatment of affective disorders. Neuroscience \& Biobehavioral Reviews, 95, 508-514. https://doi.org/10.1016/j.neubiorev.2018.10.019

Maier, S. F., \& Watkins, L. R. (1998). Cytokines for psychologists: Implications of bidirectional immune-to-brain communication for understanding behavior, mood, and cognition. Psychological Review, 105(1), 83-107.

Manigualt, A. W., Figueroa, W. S., Hollenbeck, C. R., Mendlein, A. E., Woody, A., Sinegar, S. E., Hamilton, K. R., Sclanlin, M. C., Johnson, R. C., \& Zoccola, P. M. (2018). A test of the association between mindfulness subcomponents and diurnal cortisol patterns. Mindfulness, 9, 897-904. https://doi.org/10.1007/ s12671-017-0829-4

Mary, A., Dayan, J., Leone, G., Postel, C., Fraisse, F., Malle, C., Vallée, T., Klein-Peschanski, C., Viader, F., de la Sayette, V., Peschanski, D., Eustache, F., \& Gagnepain, P. (2020). Resilience after trauma: The role of memory suppression. Science, 367, 1-13. https://doi.org/10.1126/science.aay8477
Mathur, A., Graham-Engeland, J. E., Slavish, D. C., Smyth, J. M., Lipton, R. B., Katz, M. J., \& Sliwinski, M. J. (2018). Recalled early life adversity and pain: The role of mood, sleep, optimism, and control. Journal of Behavioral Medicine, 41(4), 504-515. https://doi.org/10.1007/s10865-018-9917-8

McRae, K. (2016). Cognitive emotion regulation: A review of theory and scientific findings. Current Opinion in Behavioral Sciences, 10, 119-124. https://doi.org/10.1016/j.cobeha.2016.06.004

McRae, K., \& Gross, J. J. (2020). Emotion regulation. Emotion, 20(1), 1-9. https://doi.org/10.1037/emo0000703

Méndez Leal, A. S., \& Silvers, J. A. (2020). Neurobiological markers of resilience to early life adversity during adolescence. Biological Psychiatry. https://doi.org/10.1016/j.bpsc.2020.08.004

Meng, X., Fleury, M.-J., Xiang, Y.-T., Li, M., \& D’Arcy, C. (2018). Resilience and protective factors among people with a history of child maltreatment: A systematic review. Social Psychiatry and Psychiatric Epidemiology, 53(5), 453-475. https://doi.org/ 10.1007/s00127-018-1485-2

Mennin, D. S., Ellard, K. K., Fresco, D. M., \& Gross, J. J. (2013). United we stand: Emphasizing commonalities across cognitivebehavioral therapies. Behavior Therapy, 44(2), 234-248. https:// doi.org/10.1016/j.beth.2013.02.004

Miller, G. E., Chen, E., \& Zhou, E. S. (2007). If it goes up, must it come down? Chronic stress and the hypothalamic-pituitaryadrenocortical axis in humans. Psychological Bulletin, 133(1), $25-45$.

Miller, G. E., Chen, E., \& Parker, K. J. (2011). Psychological stress in childhood and susceptibility to the chronic diseases of aging: Moving toward a model of behavioral and biological mechanisms. Psychological Bulletin, 137(6), 959-997. https://doi.org/ $10.1037 / a 0024768$

Moore, J., Wade, T. J., Cairney, J., O'Leary, D. D., \& MacNeil, A. J. (2020). Biological embedding from adverse childhood experiences in the development of an altered inflammatory state and poor health outcomes in young adults. Journal of Immunology, 204(1 Supplement), 59.58.

Moreno-López, L., Ioannidis, K., Askelund, A. D., Smith, A. J., Schueler, K., \& van Harmelen, A.-L. (2020). The resilient emotional brain: A scoping review of the medial prefrontal cortex and limbic structure and function in resilient adults with a history of childhood maltreatment. Biological Psychiatry: Cognitive Neuroscience and Neuroimaging, 5(4), 392-402. https://doi.org/10. 1016/j.bpsc.2019.12.008

Norbury, A., Perez-Rodriguez, M. M., \& Feder, A. (2019). Neuroimaging resilience to trauma

Nusslock, R., Brody, G. H., Armstrong, C. C., Carroll, A. L., Sweet, L. H., Yu, T., Barton, A. W., Hallowell, E. S., Chen, E., Higgins, J. P., Parrish, T. B., Wang, L., \& Miller, G. E. (2019). Higher peripheral inflammatory signaling associated with lower restingstate functional brain connectivity in emotion regulation and central executive networks. Biological Psychiatry, 86(2), 153-162. https://doi.org/10.1016/j.biopsych.2019.03.968

Pechtel, P., \& Pizzagalli, D. A. (2011). Effects of early life stress on cognitive and affective function: An integrated review of human literature. Psychopharmacology (berl), 214(1), 55-70. https:// doi.org/10.1007/s00213-010-2009-2

Piazza, J. R., Almeida, D. M., Dmitrieva, N. O., \& Klein, L. C. (2010). Frontiers in the use of biomarkers of health in research on stress and aging. Journals of Gerontology Series b: Psychological Sciences and Social Sciences, 65B(5), 513-525. https://doi.org/10. 1093/geronb/gbq049

Polizzi, C. P., \& Lynn, S. J. (2021). Regulating emotionality to manage adversity: A systematic review of the relation between emotion regulation and psychological resilience. Cognitive Therapy and Research. https://doi.org/10.1007/s10608-020-10186-1 
*Poole, J. C., Dobson, K. S., \& Pusch, D. (2018). Do adverse childhood experiences predict adult interpersonal difficulties? The role of emotion dysregulation. Child Abuse \& Neglect, 80, 123-133. https://doi.org/10.1016/j.chiabu.2018.03.006

Powers, A., Stevens, J., Fani, N., \& Bradley, B. (2015). Construct validity of a short, self report instrument assessing emotional dysregulation. Psychiatry Research, 225(1-2), 85-92. https://doi.org/10. 1016/j.psychres.2014.10.020

Raison, C. L., Capuron, L., \& Miller, A. H. (2006). Cytokines sing the blues: Inflammation and the pathogenesis of depression. Trends in Immunology, 27(1), 24-31. https://doi.org/10.1016/j.it.2005. 11.006

Rasmussen, L. J. H., Moffitt, T. E., Eugen-Olsen, J., Belsky, D. W., Danese, A., Harrington, H., Houts, R. M., Poulton, R., Sugden, K., Williams, B., \& Caspi, A. (2019). Cumulative childhood risk is associated with a new measure of chronic inflammation in adulthood. Journal of Child Psychology and Psychiatry, 60(2), 199-208. https://doi.org/10.1111/jcpp.12928

Redlich, R., Stacey, D., Opel, N., Grotegerd, D., Dohm, K., Kugel, H., Heindel, W., Arolt, V., Baune, B. T., \& Dannlowski, U. (2015). Evidence of an IFN-gamma by early life stress interaction in the regulation of amygdala reactivity to emotional stimuli. Psychoneuroendocrinology, 62, 166-173. https://doi.org/10.1016/j. psyneuen.2015.08.008

Repetti, R. L., Taylor, S. E., \& Seeman, T. E. (2002). Risky families: Family social environments and the mental and physical health of offspring. Psychological Bulletin, 128(2), 330-366. https:// doi.org/10.1037//0033-2909.128.2.330

Rutter, M. (1987). Psychosocial resilience and protective mechanisms. American Journal of Orthopsychiatry, 57(3), 316-331. https:// doi.org/10.1111/j.1939-0025.1987.tb03541.x

Salari, N., Hosseinian-Far, A., Jalali, R., Vaisi-Raygani, A., Rasoulpoor, S., Mohammadi, M., Rasoulpoor, S., \& Khaledi-Paveh, B. (2020). Prevalence of stress, anxiety, depression among the general population during the COVID19 pandemic: A systematic review and meta-analysis. Globalization and Health, 16(1), 57-57. https://doi.org/10. 1186/s12992-020-00589-w

Sapolsky, R. M. (2015). Stress and the brain: Individual variability and the inverted-U. Nature Neuroscience, 18(10), 1344-1346. https:// doi.org/10.1038/nn.4109

Seery, M. D., Holman, E. A., \& Silver, R. C. (2010). Whatever does not kill us: Cumulative lifetime adversity, vulnerability, and resilience. Journal of Personality and Social Psychology, 99(6), 1025-1041. https://doi.org/10.1037/a0021344

Sheridan, M. A., \& McLaughlin, K. A. (2014). Dimensions of early experience and neural development: Deprivation and threat. Trends in Cognitive Sciences, 18(11), 580-585. https://doi.org/ 10.1016/j.tics.2014.09.001

Shields, G. S., Moons, W. G., \& Slavich, G. M. (2017). Inflammation, self-regulation, and health: An immunologic model of selfregulatory failure. Perspectives on Psychological Science, 12(4), 588-612. https://doi.org/10.1177/1745691616689091

Shields, G. S., Spahr, C. M., \& Slavich, G. M. (2020). Psychosocial interventions and immune system function: A systematic review and meta-analysis of randomized clinical trials. JAMA Psychiatry. https://doi.org/10.1001/jamapsychiatry.2020.0431

Shiota, M., \& Levenson, R. (2012). Turn down the volume or change the channel? Emotional effects of detached versus positive reappraisal. Journal of Personality and Social Psychology, 103(3), 416-429. https://doi.org/10.1037/a0029208

Southward, M. W., \& Cheavens, J. S. (2020). More (of the right strategies) is better: Disaggregating the naturalistic between- and within-person structure and effects of emotion regulation strategies. Cognition and Emotion, 1-8. https://doi.org/10.1080/02699 931.2020.1797637
Southwick, S. M., Bonanno, G. A., Masten, A. S., Panter-Brick, C., \& Yehuda, R. (2014). Resilience definitions, theory, and challenges: Interdisciplinary perspectives. European Journal of Psychotraumatology, 5. https://doi.org/10.3402/ejpt.v5.25338

Sprang, G. (1997). The Traumatic Experiences Inventory (TEI): A test of psychometric properties. Journal of Psychopathology and Behavioral Assessment, 19(3), 257-271. https://doi.org/10.1007/BF02229182

Sroufe, L. A. (2005). Attachment and development: A prospective, longitudinal study from birth to adulthood. Attachment \& Human Development, 7(4), 349-367. https://doi.org/10.1080/14616730500365928

Suglia, S. F., Koenen, K. C., Boynton-Jarrett, R., Chan, P. S., Clark, A. J., Danese, A., Faith, M. S., Goldstein, B. I., Hayman, L. L., Isasi, C. R., Pratt, C. A., Slopen, N., Sumner, J. A., Turer, A., Turer, C. B., \& Zachariah, J. P. (2018). Childhood and adolescent adversity and cardiometabolic outcomes: A scientific statement from the American Heart Association. Circulation, 137(5), e15-e28. https://doi.org/10.1161/CIR.0000000000000536

Tabibnia, G. (2020). An affective neuroscience model of boosting resilience in adults. Neuroscience \& Biobehavioral Reviews, 115, 321-350. https://doi.org/10.1016/j.neubiorev.2020.05.005

Taylor, S. E., Way, B. M., \& Seeman, T. E. (2011). Early adversity and adult health outcomes. Development and Psychopathology, 23(3), 939-954. https://doi.org/10.1017/S0954579411000411

Teicher, M. H., \& Samson, J. A. (2016). Annual research review: Enduring neurobiological effects of childhood abuse and neglect. Journal of Child Psychology and Psychiatry, 57(3), 241-266. https://doi.org/10.1111/jcpp.12507

Teicher, M. H., Samson, J. A., Anderson, C. M., \& Ohashi, K. (2016). The effects of childhood maltreatment on brain structure, function and connectivity. Nature Reviews Neuroscience, 17(10), 652-666. https://doi.org/10.1038/nrn.2016.111

*Tinajero, R., Williams, P. G., Cribbet, M. R., Rau, H. K., Silver, M. A., Bride, D. L., \& Suchy, Y. (2020). Reported history of childhood trauma and stress-related vulnerability: Associations with emotion regulation, executive functioning, daily hassles and pre-sleep arousal. Stress and Health, 36(4), 405-418. https://doi.org/10.1002/smi.2938

Troy, A. S., Brunner, A., Shallcross, A. J., Friedman, R., \& Jones, M. C. (2018). Cognitive reappraisal and acceptance: Effects on emotion, physiology, and perceived cognitive costs. Emotion, 18(1), 57-84. https://doi.org/10.1037/emo0000371

Troy, A. S., Ford, B. Q., McRae, K., Zarolia, P., \& Mauss, I. B. (2017), Change the things you can: Emotion regulation is more beneficial for people from lower than from higher socioeconomic status. Emotion, 17(1), 141-154. https://doi.org/10.1037/emo0000210

Troy, A. S., \& Mauss, I. B. (2011). Resilience in the face of stress: Emotion regulation as a protective factor. In B. T. L. Steven, M. Southwick Dennis Charney, \& M. J. Friedman (Eds.), Resilience and mental health: Challenges across the lifespan (pp. 30-44). Cambridge University Press.

van IJzendoorn, M. H., Bakermans-Kranenburg, M. J., Coughlan, B., \& Reijman, S. (2020). Annual research review: Umbrella synthesis of meta-analyses on child maltreatment antecedents and interventions: Differential susceptibility perspective on risk and resilience. The Journal of Child Psychology and Psychiatry, 61(3), 272-290. https://doi.org/10.1111/jcpp.13147

VanTieghem, M. R., \& Tottenham, N. (2018). Neurobiological programming of early life stress: Functional development of amygdala-prefrontal circuitry and vulnerability for stress-related psychopathology. Current Topics in Behavioral Neuroscience, 38, 117-136. https://doi.org/10.1007/7854_2016_42

Villalba, D. K., Lindsay, E. K., Marsland, A. L., Greco, C. M., Young, S., Brown, K. W., Smyth, J. M., Walsh, C. P., Gray, K., Chin, B. C., \& Creswell, J. D. (2019). Mindfulness training and systemic low-grade inflammation in stressed community adults: Evidence from two randomized controlled trials. PLoS One, 14(7). https:// doi.org/10.1371/journal.pone.0219120 
Wadsworth, M. E. (2015). Development of maladaptive coping: A functional adaptation to chronic, uncontrollable stress. Child Development Perspectives, 9(2), 96-100. https://doi.org/10. 1111/cdep. 12112

Warner, E. A., Hernandez, T., \& Veilleux, J. C. (2020). Examining facets of mindfulness in the relationship between invalidating childhood environments and emotion regulation. Psychological Reports, 1-16. https://doi.org/10.1177/0033294120933151

Webb, T. L., Miles, E., \& Sheeran, P. (2012). Dealing with feeling: A meta-analysis of the effectiveness of strategies derived from the process model of emotion regulation. Psychological Bulletin, 138(4), 775-808. https://doi.org/10.1037/a0027600

Yamamoto, T., Toki, S., Siegle, G. J., Takamura, M., Takaishi, Y., Yoshimura, S., Okada, G., Matsumoto, T., Nakao, T., Muranaka, H., Kaseda, Y., Murakami, T., Okamoto, Y., \& Yamawaki, S. (2017). Increased amygdala reactivity following early life stress: A potential resilience enhancer role. BMC Psychiatry, 17(1), 27. https://doi.org/10.1186/s12888-017-1201-x
Yoon, S., Howell, K., Dillard, R., McCarthy, K. S., Napier, T. R., \& Pei, F. (2019). Resilience following child maltreatment: Definitional considerations and developmental variations. Trauma, Violence, \& Abuse, 1524838019869094. https://doi.org/10.1177/ 1524838019869094

Zautra, A., Hall, J., \& Murray, K. (2008). Resilience: A new integrative approach to health and mental health research. Health Psychology Review, 2(1), 41-64. https://doi.org/10.1080/17437 190802298568

Zhang, H., \& Zhang, L. (2018). The effects of early life stress on emotion regulation and the underlying mechanisms. Advances in Psychological Science, 26(7), 1193-1203. https://doi.org/10.3724/ sp.j.1042.2018.01193 